\title{
Are sensory attributes and acceptance influenced by nutritional and health claims of low-sodium salami? Preliminary study with Brazilian consumers
}

\author{
Marcio Aurélio de Almeida ${ }^{1}$; Nilda Doris Montes Villanueva ${ }^{2}$, Erick Saldaña ${ }^{1}$; Jair \\ Sebastião da Silva Pinto ${ }^{1}$; Carmen J. Contreras-Castillo ${ }^{1, *}$ \\ 1 Universidade de São Paulo, Escola Superior de Agricultura "Luiz de Queiroz", Departamento de Agroindústria, \\ Alimentos e Nutrição. Piracicaba, SP 13418-900, Brazil. \\ ${ }^{2}$ Universidad Católica Sedes Sapientiae, Facultad de Ingeniería Agraria, Esq. Constelaciones y Sol de Oro S/N \\ Urbanización Sol de Oro, Los Olivos - Lima - Peru.
}

Received July 23, 2017. Accepted November 26, 2017.

\begin{abstract}
The first contact between consumers and the food product is usually the packaging and it's labelling. Therefore, it is the primary means to generate consumer's expectations. The aim of the present work was to evaluate the influence of nutritional and health claims on acceptance of salami with reduced sodium content, aimed at finding guidance for the product reformulation. Sixty consumers evaluated four samples of salami. The overall acceptance was evaluated using a nine-point hedonic scale, and the attributes color, tenderness, characteristic flavor and salt content, were evaluated by 7 - point just-about-right (JAR) scale. For the expectation test, overall liking of salami with reduced sodium content was evaluated by consumers under three conditions: (1) blind test (B); (2) expectation generated by nutritional and health claims (E), and (3) consumers re-tasted the salami having the nutrition and health claims available (R). Student's t-tests performed on data indicated no significant differences $(\mathrm{p}>0.05)$ between the mean acceptance under the blind $(\mathrm{B})$ and real $(\mathrm{R})$ conditions, although expectation ratings $(\mathrm{E})$ were significantly higher than $(\mathrm{B})(\mathrm{p} \leq 0.05)$. However, linear regression of $(\mathrm{R}-\mathrm{B}) \mathrm{x}(\mathrm{E}-\mathrm{B})$ ratings revealed a major assimilation effect of expectation, especially under negative disconfirmation $(\mathrm{E}>\mathrm{B})$. Contrast effect was also observed, but to a lesser extent. The results showed that saltiness attribute was not decisive in decreased acceptance according to the JAR scale, but it was relevant in the aftertaste generated by adding salt substitutes. Finally, nutritional and health claims had little effect on consumer acceptance.
\end{abstract}

Keywords: nutrition and health claims; expectation test; consumers' behavior; reduced sodium content; meat product.

\section{Introduction}

Food production involves several challenges, ranging from satisfying the basic nutritional needs of consumers, to catering for the complex demands associated with sensory characteristics of foods. Currently, researchers of Meat Science and Technology related to development of new meat products are focusing part of their research on the development of sausages with a low sodium content and good consumer acceptance (de Almeida et al., 2016;
Yotsuyanagi et al., 2015). Conventional meat products, such as salami, have a high value-added reaching up to six times the price of meat "in natura", and are generally well accepted by brazilian consumers. However, they represent an important source of sodium, given that between 1.5 and $3.0 \%$ of $\mathrm{NaCl}$ is added during their production. At the end of this process, the $\mathrm{NaCl}$ concentration can reach between 2.5 and $5.0 \%$ (Cichoski et al., 2009). Nevertheless, average daily dietary salt intake is much higher than the 
recommended level of less than $5 \mathrm{~g}$ of salt per day, equivalent to $2 \mathrm{~g}$ of sodium per day (WHO, 2012).

The main problems associated with the development of products with low sodium content are related to flavor and texture modification. This caused by the reduction in $\mathrm{NaCl}$, developing a bitter and metallic taste, which in turn is caused by the addition of salt substitutes (Aaslyng et al., 2014; Desmond, 2006; dos Santos et al., 2015). A strategy to mask the sensory characteristics generated by the addition of substitute salts is the addition of starter cultures, because it helps in obtaining low molecular weight (LMW) peptides on fermented meat products, enhancing the texture, color and flavor (López et al., 2015a; 2015b).

On the other hand (Behrens et al., 2007 and Jaeger, 2006) reported that the foods perception is affected by intrinsic factors such as taste, odor, texture, among others, which play a fundamental role in the acceptance and purchase intention of the product by consumers. It is also important to consider extrinsic factors (non-sensory factors) such as the label, the price, the packaging, and nutritional and health claims, given that they influence the consumer's perception of the product and create expectations, as they represent the first contact between an individual and a product (Jaeger, 2006). Font-i-Furnols et al. (2014) define expectations "as a group of feelings and/or beliefs inherent to humans concerning the likelihood that something will happen in a certain way or that a product will have certain characteristics". Previous studies have shown that the characteristics of the packaging, and particularly those of the label, can influence the expectation of consumers and hedonic assessments of food products (Behrens et al., 2007; Carrillo et al., 2012). Therefore, the communication of a product's health and nutritional properties is of extreme importance. One of the methods used to assess the sensory characteristics that affect acceptance is the JAR scale, based on levels ranging from "much too strong" to "much too weak", with "just about right" as the center point. The advantage of JAR scaling combines the measurement of attribute intensity and consumer acceptance (Rothman and Parker, 2009).

In this context, the aim of the present study was to compare a low sodium salami with three commercial salamis, considering acceptance and ideal intensity of sensory attributes using JAR scale and penalty analysis. In addition, the expectation generated by nutritional and health claims on the acceptance of the low sodium salami was modeled.

\section{Material and methods}

\subsection{Samples}

Four salami samples with different sodium content were studied. Three commercial brands of salami were chosen for being widely commercialized on the Brazilian market. Commercial samples were compounds: salami with $2562 \mathrm{mg}$ of sodium per $100 \mathrm{~g}$ of sample (sample 428), salami with $1612 \mathrm{mg}$ of sodium per $100 \mathrm{~g}$ of sample (sample 635) and salami with 1790 $\mathrm{mg}$ of sodium per $100 \mathrm{~g}$ of sample (sample 372). No additional information was available due to confidentiality of the commercial brands. The fourth sample with $55 \%$ of sodium reduction was manufactured in the meat processing plant (sample 580), with 3 replications (independent salami processing), using the following meat ingredients: pork shoulder $(60 \%)$, beef chuck (20\%) and pork back fat $(20 \%)$, together with the following nonmeat ingredients: sodium nitrate $(0.015 \%)$, sodium nitrite $(0.015 \%)$, sodium erythorbate $(1.0 \%)$, dextrose $(0.75 \%)$ and spices $(0.32 \%)$, based on $100 \%$ raw meat. Based on previous studies López et al. (2015a, 2015b) selected autochthonous starter cultures (Enterococcus mundtii CRL 35, Staphylococcus vitulinus GV 318 and Lactobacillus sakei CRL 1862) isolated from an artisanal fermented sausage of Tucumán - Argentina, provided by Centro de Referencia para Lactobacilos (CERELA) were added at a concentration 
of $8 \log \mathrm{CFU} / \mathrm{g}$ of starter cultures. The salami was processed in the following stages: firstly, the meat was minced using discs with holes of 10,8 and $5 \mathrm{~mm}$ for pork, beef and pork back fat, respectively. The meat mixture was prepared in a mixer Beccaro MB - 25 series 0010-2476 (Beccaro - Brazil), during 5 minutes. The meat mixture obtained was stuffed in reconstituted Viscofan collagen casings (length of $35 \mathrm{~cm}$ and diameter of $4.5 \mathrm{~cm}$ ), which were later fermented and left to ripen. During the fermentation process, the temperature ranged from $21{ }^{\circ} \mathrm{C}$ to $23{ }^{\circ} \mathrm{C}$, while the relative humidity ranged from $85 \%$ to $90 \%$. These conditions were maintained until the $\mathrm{pH}$ reached a level of between 5.0 and 5.2, measured using a potentiometer (Oakton $\mathrm{pH} 300$ series 35618, Vernon Hills, IL, USA; equipped with a Digimed electron puncture). Subsequently, the salami was ripened at a temperature of between $17{ }^{\circ} \mathrm{C}$ and $19{ }^{\circ} \mathrm{C}$ ( $75 \%$ relative humidity) for 20 to 25 days, until 0.90 of water activity. The water activity was determined at $25{ }^{\circ} \mathrm{C}$ using a water activity meter (AquaLab 4TE, Decagon Devices, Inc., USA).

\subsection{Physicochemical characteristics}

The sodium content in the salami was determined following the AOAC recommendations. Five grams of the sample were weighed directly on the capsule (previously heated in a muffle at $550^{\circ} \mathrm{C}$ ). The capsule with the sample was carbonized on a hot plate and then calcined in a muffle at $550{ }^{\circ} \mathrm{C}$. When the capsules had cooled, the ashes were dissolved with $2.5 \mathrm{~mL}$ of nitric acid (65\%) and transferred to a volumetric flask of $50 \mathrm{~mL}$. The readings were conducted using a flame photometer (model B462, Micronal, SP, Brazil). Moisture, proteins and lipids were determined following the AOAC recommendations (AOAC, 2000).

\subsection{Microbiological analysis}

Twenty-five grams of each salami were mixed with $225 \mathrm{~mL}$ of sterile peptone water at $0.1 \%$ (Difco Laboratories, Detroit, MI, USA) and homogenized (Lab-blender
400, Seward medical, London, U.K.). Decimal dilutions were prepared and inoculated in Plate Count Agar (PCA) and Man, Rogosa Sharpe (MRS), and Mannitol Salt Agar (MSA) for aerobic mesophilic microorganisms, lactic acid bacteria, and Staphylococcus sp., respectively.

\subsection{Sensory evaluation}

The sensory evaluations were carried out in individual tasting booths in the sensory analysis laboratory of the Departamento de Agroindústria, Alimentos e Nutrição, Escola Superior de Agricultura "Luiz de Queiroz", Universidade de São Paulo (LAN/ESALQ/USP). At each evaluation, $20 \mathrm{~g}$ of each sample was served at $20^{\circ} \mathrm{C}$ under white plastic plates, labeled with three-digit random numbers. For the JAR task, samples were presented in a sequential monadic way, following a Latin Square design to balance the effects of presentation order of samples. Mineral water was used for rinsing between samples. The present study was registered and approved by the Ethics Committee of Human Research of the LAN/ESALQ/USP under protocol number 104/2012. The sequence of the sensory evaluation is shown in Figure 1.

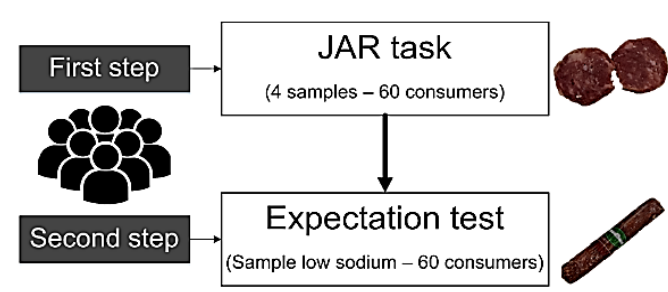

Figure 1. Design of the sensory evaluation sequence.

\subsubsection{Consumers}

Sixty habitual salami consumers with ages ranging between 18 to 55 years old (19 men and 41 women) were recruited among the staff and student population of LAN/ESALQ/USP. Consumers were recruited based on the following criteria: (a) like of salami, (b) consuming salami at least twice a month, and (c) interest in participating in the study. 


\subsubsection{JAR task}

Consumers were accommodated in individual tasting booths, where they received the salami samples to evaluated how much they liked (or disliked) using a nine-point hedonic scale $(1=$ dislike extremely, $5=$ neither like nor dislike, $9=$ like extremely). Next, they evaluated the texture, characteristic flavor, color and saltiness using the 7 - point JAR scale $(1=$ much less than ideal, $4=$ ideal, and $7=$ much more than ideal) (Popper, 2014). These attributes were measured in terms of being "much too strong", "much too weak" and "just about right", from the point of view of the consumer's perception.

\subsubsection{Evaluation of consumer expecta- tion}

The acceptance test to evaluate the consumer expectation was carried out using a nine-point hedonic scale $(1=$ dislike extremely, $5=$ neither like nor dislike, $9=$ like extremely) in a single session, divided into three stages as follows:

Blind test (B): consumers were only informed that the samples were salamis. After tasting each sample, they were asked to rate overall acceptance.

Expected liking (E): in this stage, health claims framed in a short text about the advantages of consuming sodium-reduced products were presented to the consumers. In order to highlight the health characteristics of the new product, the inscriptions "Salami with a reduced salt content" and "Made with 55\% less salt" were used (Figure 2). In addition, consumers were asked to read the following: "According to the World Health Organization (WHO), Brazilians consume three times more sodium chloride (salt) than the recommended amount. The high salt intake and consequently, high sodium intake, causes serious damage to health such as blood pressure and stroke. Among the many sources of salt intake are industrialized foods, and in the case of industrialized meat products, salami has on average about $5 \%$ salt content. Thus, in recent years, studies have been made to reduce the amount of sodium in food. Our new product is an Italian type salami with low salt content, where it achieved a reduction of 55\% sodium. This new formulation is a healthy product that can be consumed by children, adolescents, adults and also seniors!" and then rate the expected overall acceptance.

Real evaluation $(\mathrm{R})$ : the consumers were asked to re-read the text and re-tasted a salami sample rating the overall acceptance.

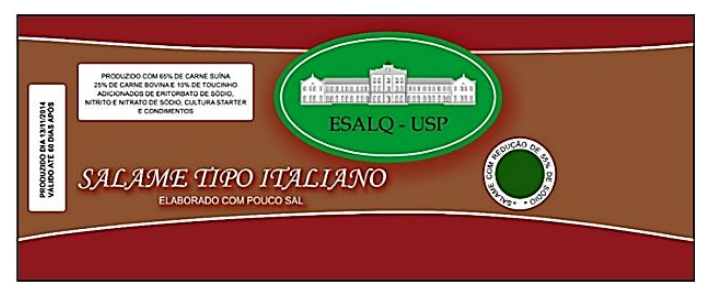

Figure 2. Label created for the present study.

\subsection{Data analysis}

For the JAR task, the acceptance data were analyzed using three-way ANOVA ( $\mathrm{p}<$ 0.05 ), considering the sample, presentation order and consumer as sources of variation, followed by the Tukey's HSD test for pairwise means comparisons ( $\mathrm{p}<$ 0.05), using Statistica 12 (StatSoft) software. The results of JAR scale were analyzed through penalty analysis and principal components analysis (Rothman and Parker, 2009) using XLSTAT software (Addinsoft, New York, USA). For expectation data, in order to analyze the salami with low sodium content in relation to acceptance, mean and standard deviation values were obtained in each of the three stages ( $\mathrm{B}, \mathrm{E}$ and $\mathrm{R}$ conditions). Paired $\mathrm{t}-$ test was performed to assess the differences between the acceptance in the $B$ and $R$ conditions (R-B), in the real and expectation conditions (R-E), and in the expectation and blind conditions (E-B) (p $<0.05$ ). In order to visualize the effect of expectation on the acceptance, individual differences between ratings in real and blind conditions $(\mathrm{R}-\mathrm{B})$ versus the degree of disconfirmation (E- B) were plotted on a dispersion diagram to fit a simple linear regression model. Also, the proportions of consumers in assimilation or contrast quadrants, as well as those showing no effect, were examined. 


\section{Results and discussion}

\subsection{Physicochemical characteristics}

The sodium content in the salami developed in the laboratory $(880 \mathrm{mg}$ of sodium / $100 \mathrm{~g}$ of salami) had a reduction of approximately 55\%, compared to other similar products currently produced in the Brazilian market. The most popular commercial brands of salami in Brazil contain between 1612 and $2562 \mathrm{mg}$ of sodium $/ 100 \mathrm{~g}$ of salami. The prototype salami exhibited acceptable water activity values (0.90), given that the maximum value should not exceed 0.92 , according to Brazilian regulation (Brasil, 2000). Moisture content was $35.2 \%$ and the protein content was $31.7 \%$, which are within the regulations (maximum acceptable moisture level is 35\%) (Brasil, 2000). This value was below that found by Zanardi et al. (2004) which reported 31.9\% moisture. Another factor that needs to be considered during the development of meat products is the lipid content. The product assessed here exhibited a lipid content of $28.9 \%$ and satisfied Brazilian regulation, which allows for a maximum of $32 \%$ fat (Brasil, 2000). This value has been close to that found in a previous study (Marangoni and Fernandes, 2011).

It was observed that low sodium concentration (1.0\% of sodium chloride) and added potassium and calcium chloride were sufficient to maintain the adequate ionic strength, aiding the water loss in the drying period. Therefore, sodium reduction did not alter the mechanism of dehydration, expressed as the final Aw of the salamis, these being technologically stable. It is likely that low lipid content and high protein content helped to increase the available proteins for binding with water. It is important to mention that the protein and Aw content of fermented meat products are considered as the main physicochemical characteristics related to consumer acceptance (López et al., 2012).

\subsection{Microbiological analysis}

All treatments showed counts (aerobic mesophilic microorganism and Staphy- lococcus sp.) within the limits established by Brazilian Health Surveillance Agency (Brasil, 2001). Bacterial counts helped to monitor the inoculated population at the beginning of the manufacture process and to analyze its growth during the drying and ripening stages on prototype salami. The initial inoculation $(8-9 \log \mathrm{CFU} / \mathrm{g}$ of starter cultures) was within the limits set based on a previous research (López et al., 2015b). The initial count was as expected and this population increased during the drying and ripening stages of the salami. This possibly indicates that the acidity produced during the fermentation process did not greatly affect the growth of starter cultures. According to Rantsiou and Cocolin (2006) three days after fermentation, the lactic bacteria quantity added as a culture starter should reach $7-8 \log$ CFU/g, which should remain relatively stable until the end of their production. According to the microbial counts, the salami used in this research were safe and fit for consumption. The presence of starter cultures during salami processing is very important because of its positive effect on the production of flavor compounds generated during proteolysis. In the present study it was possible to maintain the high counts of the starter cultures during the whole drying stage of the salami, which boosted their effect on the sensorial characteristics and consumer acceptance.

\subsection{Sensory analysis}

\subsubsection{JAR task}

In Figure 3, the JAR data were displayed in three groups. The first group was composed of the scores 1, 2 and 3 and represented the responses "much too weak". The second group was formed by the score 4, which represented "just about right", and the third group was formed by the scores 5, 6 and 7, which represented the responses "much too strong". Consumers perceived the sample 580 (lowsodium salami) as darker. Sample 428 (commercial salami with $2562 \mathrm{mg}$ of sodium $/ 100 \mathrm{~g}$ of sample) and sample 635 (commercial salami with $1612 \mathrm{mg}$ of 
sodium $/ 100 \mathrm{~g}$ of sample) exhibited higher percentages of "just about right" for all attributes. These responses were expected due to the fact that these products are the most consumed on the Brazilian market and have a high concentration of $\mathrm{NaCl}$. Conversely, the sample 372 (commercial salami with $1790 \mathrm{mg}$ sodium/100g sample) exhibited a higher percentage of "much too strong" for the attributes texture and saltiness. For "saltiness" attribute, the prototype sample (580) exhibited elevated percentages for "much too weak" and "just about right". The fact that a high number of consumers thought the sample was "just about right" is a favorable result for the product in question, given that many consumers did not notice the substitution of $\mathrm{NaCl}$ by a combination of $0.25 \%$ potassium chloride $+0.25 \%$ calcium chloride. However, the fact that the perception of saltiness was not affected does not mean that the other sensory attributes were ignored. Texture of the salami was considered "much too weak" by a large number of consumers. The characteristic taste of the salami was also considered "much too weak" or "much too strong" by a large percentage of consumers.
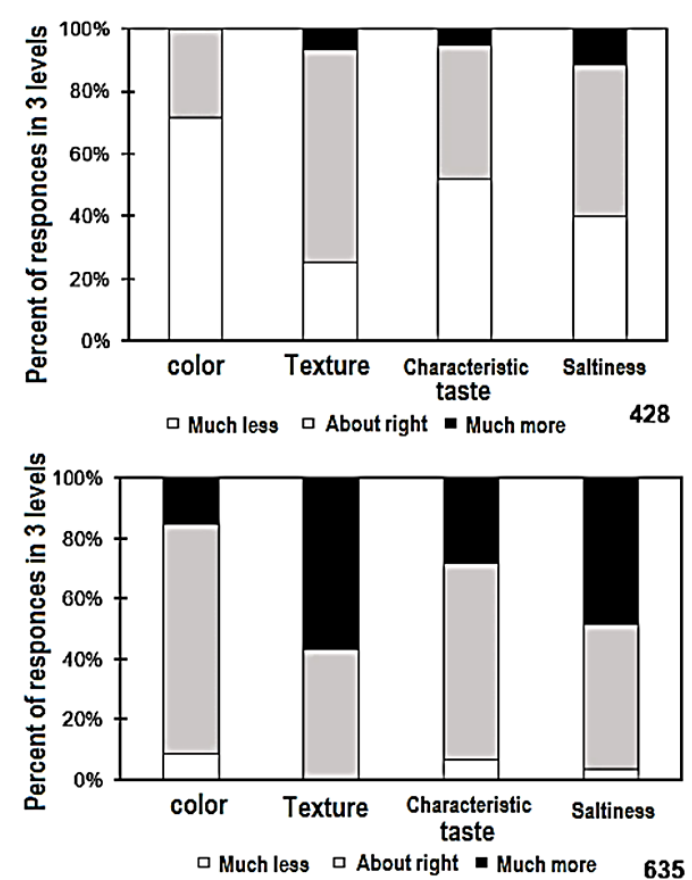

Samples 635 and 428 were perceived as "just about right" for texture, characteristic taste and saltiness by a high percentage of consumers and thus, a high acceptability was recorded. For samples 372 and 580, the percentage of consumers that perceived these attributes as "just about right" was lower, which would indicate a possible rejection of the product in the market.

In Figure 4 the acceptance of all samples is shown, where 372 and 580 presented the lowest values of acceptance. The possible rejection of these samples was due to the high percentage of consumers that perceived the texture and characteristic taste as "more" or "less" than ideal (just about right). For the low-sodium salami (580), the rejection was due probably to the "soft" texture, caused by the reduction in sodium chloride, or the bitter, acidic and metallic taste, caused by the substitution of sodium chloride by a combination of potassium chloride and calcium chloride. According to Agudelo et al. (2015), penalty analysis helps identify possible sensory improvements in the product, driving the increase or decrease of intensity of a sensory attribute to be close to "just about right".
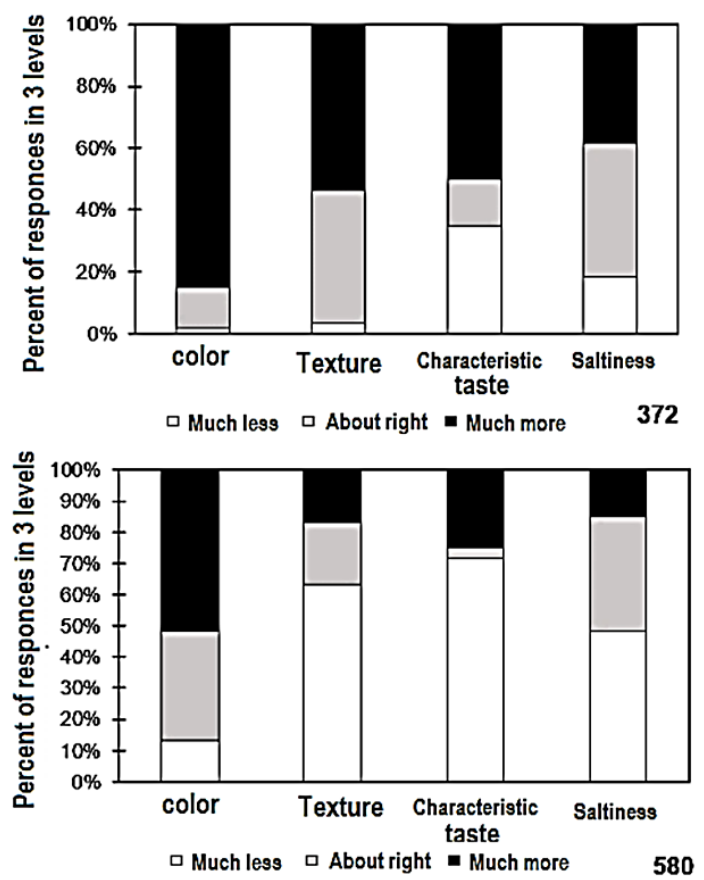

Figure 3. JAR scale percentages of responses grouped in three levels. 


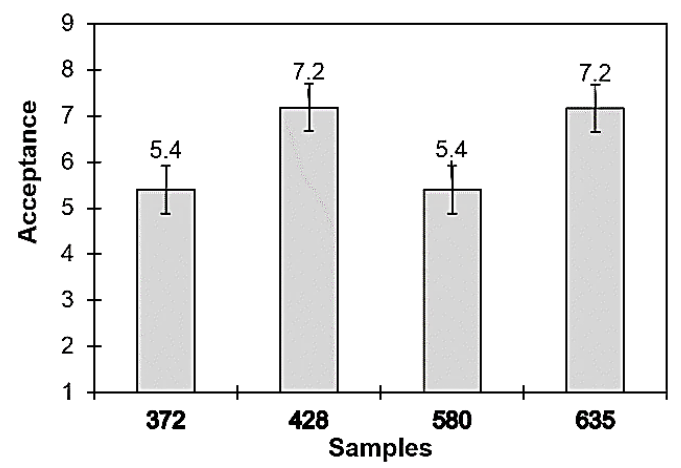

Figure 4. Acceptance of the salami samples. 372, 428, 635: Commercial samples. 580: laboratory prototype.

Attributes contained in the upper right section of each perceptual map (Figure 5) were considered susceptible to modifycation when at least $20 \%$ of the consumers reported that they were "much too strong", and "much too weak" (Xiong and Meullenet, 2006) decreasing more than one on nine-point hedonic scales (Popper, 2014). Figure 5 confirms the attributes that were penalized more than one point by $20 \%$ of the consumers and were related with the characteristic flavor ("much too strong" and "much too weak") and saltiness ("much too weak"). The attributes in the upper right quadrant of the Figure 5 represent a greater impact on the mean drop in acceptance.
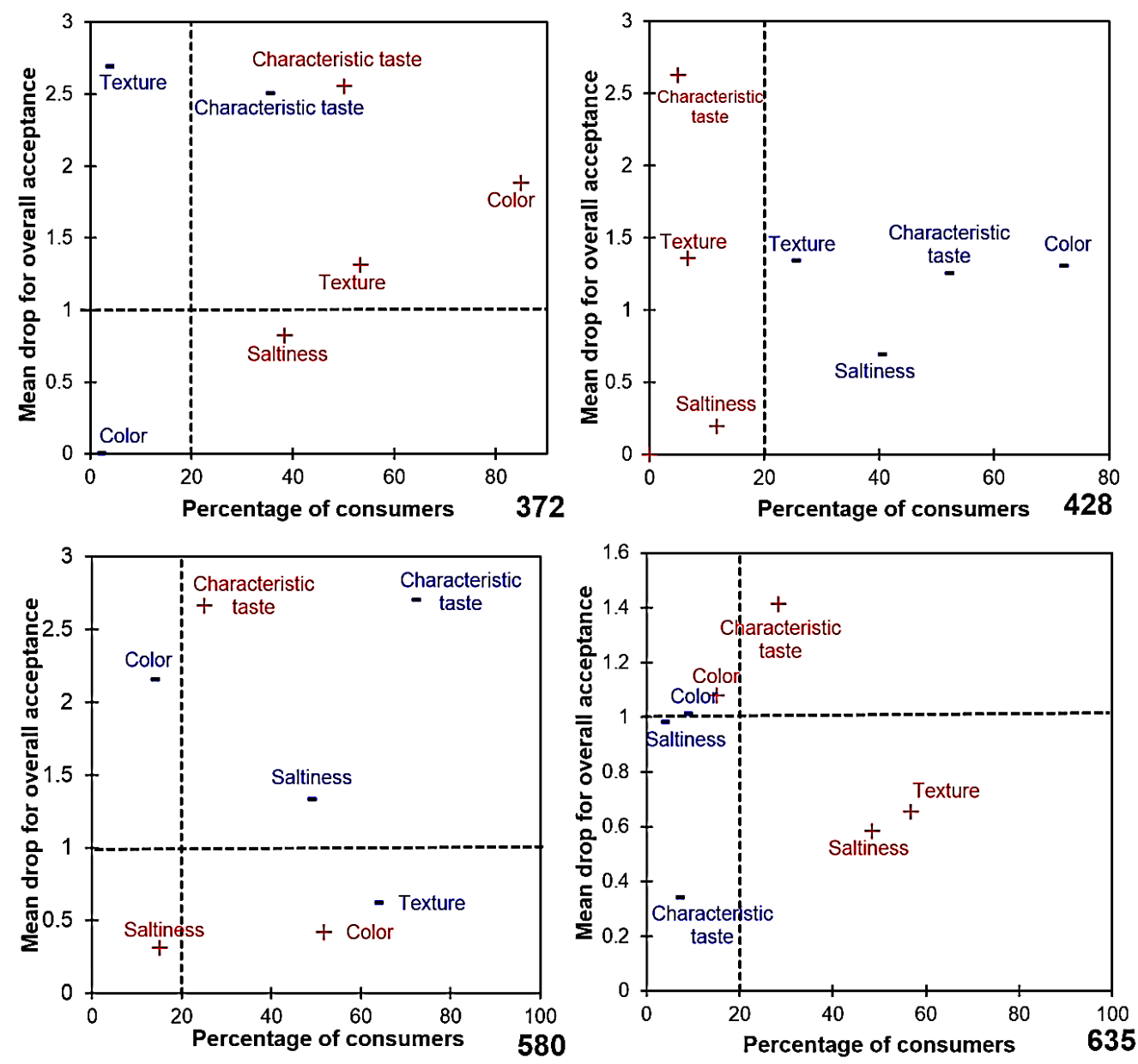

Figure 5. Representation of the penalty analysis of the samples showing the mean drop in acceptance vs. the percentage of consumers. The cut-off point was a decrease of one point in a hedonic nine-points scale perceived by $20 \%$ of the consumers who indicated that an attribute was "much too weak" (-) or "much too strong" (+) than "just about right". 372, 428, 635: Commercial samples. 580: laboratory prototype. 
When comparing sample 580 with the other samples assessed in the present study, the attributes classified as "much too strong" for sample 372 were: texture, color and characteristic taste, the latter of which was also reported as "much too weak". The attributes penalized and different from sample 580 were color and texture. It can be assumed that a certain "off flavor" in sample 580 was very intense and thus, decreased the penalty of the other attributes.

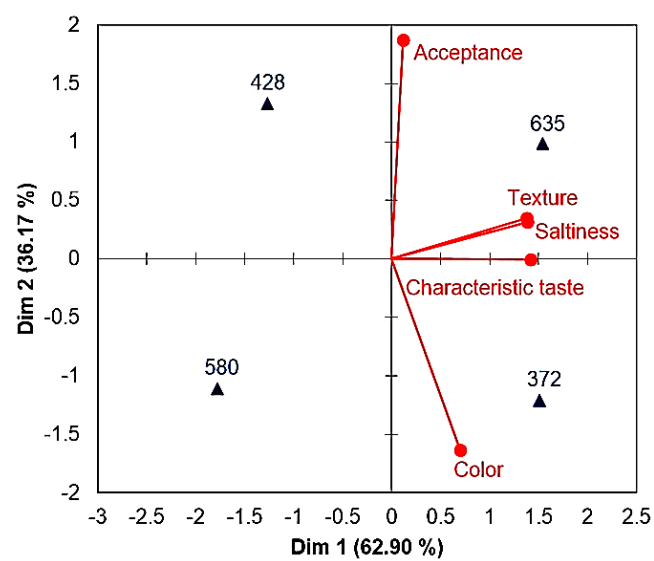

Figure 6. Principal component analysis of data JAR for salami samples. Salami 580 - salami with low sodium content produced for the present study. 372, 428, 635: Commercial samples. 580: laboratory prototype.

Figure 6 displays the biplot of the principal components analysis (PCA), which describe relationships between the JAR attributes, acceptance, and samples. For this analysis, the variance explained by the two principal components was $99 \%$, indicating that little information is lost in the other principal components. The attributes texture, saltiness and characteristic taste were correlated with the first principal component, whereas acceptance and color were correlated with the second principal component.

The first principal component differentiated samples 580 and 428 from samples 372 and 635 due to attributes correlated with this component. This behavior could be due to the fact that samples 635 and 372 were perceived as "just about right" or "much too strong", whereas samples 420 and 580 were perceived as "much too weak". The reasons for this behavior corroborate the results obtained in the penalty analysis, which was explained in detail above.

Concerning second principal component, samples 428 and 635 differed from samples 580 and 372 , due to the acceptance and color, since these attributes were correlated with this component. It is interesting to note that the two components separate the samples, due to the fact that each one represents different sensory attributes.

\subsubsection{Evaluation of consumer expecta- tion}

Three affective sensory evaluations were conducted to study the effect of the expectations generated by the nutritional and health claims. The responses are shown in Table 1, with the mean acceptance value for the low sodium salami (laboratory prototype) in each of the three stages of the evaluation ( $\mathrm{C}, \mathrm{E}$ and $\mathrm{R}$ conditions). Positive disconfirmation was observed in Table 1 , since $\mathrm{E}>\mathrm{B}(\mathrm{p}<0.001)$. Therefore, the contrast and assimilation theories were studied.

In the first stage of the present study (blind condition), the sample of salami with a low sodium content obtained a mean acceptance of 6.7 , which refers to the category "like moderately".

Table 1

Mean acceptance of salami with low sodium content in B, E and R conditions

\begin{tabular}{ccccccc}
\hline \multicolumn{3}{c}{ Stages of the evaluation } & \multicolumn{3}{c}{ Student's t-test } \\
\hline $\begin{array}{c}\text { Blind } \\
(\mathrm{B})\end{array}$ & $\begin{array}{c}\text { Expected } \\
(\mathrm{E})\end{array}$ & $\begin{array}{c}\text { Real } \\
(\mathrm{R})\end{array}$ & Real - Blind & P-value & $\begin{array}{c}\text { Expected - } \\
\text { Blind }\end{array}$ & p-value \\
\hline 6.7 & 7.8 & 6.9 & 0.2 & 0.34 & 1.1 & $<0.001$ \\
\hline
\end{tabular}

Significant effects at 5\% significance are highlighted in bold. 
After reading the text, the consumers assessed the acceptance value that they believed the salami would obtain, thereby completing the expected condition. The mean acceptance was 7.8 , indicating that in general, the consumers thought that the product would be "like very much". However, in the final stage of the test (real condition), when the consumers reassessed the samples after rereading the information about the same sample, the mean acceptance was 6.9, indicating that the consumers evaluated the sample only as "like moderately". Thus, the real condition (R) demonstrated that the claims described in the text and label did not have a significant increase $(p>0.05)$ of the acceptance of the salami, in relation to the blind test. This behavior was probably because the salami exhibited strange sensory characteristics (mainly, characteristic taste), as a result of the sodium substitution reformulation.

When the expected acceptance is greater than blind acceptance (E > B), one can say that there is negative disconfirmation of the nutritional and health claims of lowsodium salami. To better explore the negative disconfirmation of the assimilation and the contrast, the consumers were represented on a scatter plot with E-B on $\mathrm{X}$ axis and R-B on $\mathrm{Y}$ axis. Figure 7 shows that in quadrant $1,38.3 \%$ of the consumers stated that the product was worse than expected, in other words, the $\mathrm{E}$ value was greater than the $\mathrm{B}$ value $(\mathrm{E}>\mathrm{B})$. This behavior probably caused little assimilation of information, and consequently, increased acceptance slightly in relation to the blind condition $(\mathrm{R}-\mathrm{B}=0.2)$ (Table 1$)$. In quadrant $2,0 \%$ of the consumers stated that the salami was better than expected (E $<\mathrm{B}$ ), demonstrating that the claims had no generated positive expectations. In quadrant $3,8.3 \%$ of the consumers stated that the salami was better than expected (E < B). However, in the final evaluation, the claims did not contribute positively and did not increase the acceptance of the salami $(\mathrm{R}<\mathrm{B})$. In fourth quadrant, $8.3 \%$ of the consumers stated that the product was worse than their expectation $(\mathrm{E}>\mathrm{C})$, with a decrease in acceptance in relation to the initial blind test $(\mathrm{R}<\mathrm{C})$, clearly indicating a contrast between expected and real conditions.

Given the responses obtained, it is possible to conclude that the information contained in the text did not "convince" the consumer to alter their perception of the product, due to the salami presenting more discrepant sensory characteristics than expected, causing a bad sensorial experience and obviously a low acceptance of the consumers. In addition, with the aim of increasing acceptance, technological improvements can be made such as, modifications in the morphology of salt crystals so that it can dissolve more quickly in the saliva and can increase the saltiness perception with a low concentration of sodium (Quilaqueo et al., 2015), since substitutions of $\mathrm{NaCl}$ by other salts generate strange flavors that are impossible to mask.

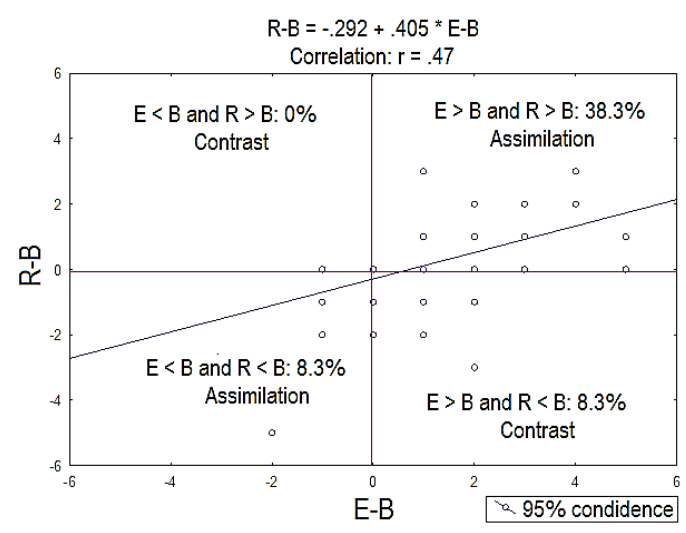

Figure 7. Linear regression to evaluate the effect of expectations on acceptance of the reduced sodium salami. $(\mathrm{B})=$ blind, $(\mathrm{E})=$ expected, and $(\mathrm{R})=$ real conditions.

\subsection{Limitations of the study}

In the present study, the results show that great care must be taken to avoid drastic alterations to the characteristic flavor of salami when reducing the salt-content. It is important to note that the reduced sodium salami showed a close acceptance of 7 , and would therefore be accepted by consumers. Similar results were reported by (Guardia et al., 2006) for fermented meat products and by de Almeida et al. (2016) for Italian 
salamis with a sodium reduction of approximately $50 \%$. However, the results discussed in the present study have to be taken with caution as there are some strongly penalized sensory attributes: mainly the characteristic taste, which probably caused an incomplete assimilation of the health claim. Therefore, it is advisable to carry out more studies with a larger number of consumers, with different claims and with lower sodium reductions.

\section{Conclusions}

The salami developed for the present study was not well accepted by consumers. The JAR scale was found to be an adequate instrument for the development of products and, together with the penalty analysis, it indicated that the main driver of preference is the characteristic taste. The absence of characteristic taste of salami caused the health claims on the label to have little influence on consumer acceptance of the product due to an incomplete assimilation of these claims. Salami is traditionally consumed as a product with a high salt content and as such, less drastic reductions in salt should be attempted, in order to preserve the characteristic flavor of this type of product. In addition, other strategies should be sought to avoid strange tastes.

\section{Acknowledgments}

The authors are grateful to the "Fundação de Amparo à Pesquisa do Estado de São Paulo" (FAPESP, Brazil) for funding the project $\mathrm{n}^{\circ}$ 2012/07113-2, "Coordenação de Aperfeiçoamento de Pessoal de Nível Superior" (CAPES) for the M.A. de Almeida Ph.D scholarship and Cienciactiva for the E. Saldaña Ph.D Scholarship (Contract 1042016-FONDECYT) from the "Consejo Nacional de Ciencia, Tecnología e Innovación Tecnológica" (CONCYTEC, Peru).

\section{References}

Aaslyng, M.D.; Vestergaard, C.; Koch, A.G. 2014. The effect of salt reduction on sensory quality and microbial growth in hotdog sausages, bacon, ham and salami. Meat Science 96: 47-55.

Agudelo, A.; Varela, P.; Fiszman, S. 2015. Fruit fillings development: A multiparametric approach. LWT Food Science and Technology 61: 564-572.
AOAC. Association of Official Analytical Chemists. Official methods of analysis of the AOAC. 17ed. Gaithersburg, 2000.

Behrens, J.H.; Vilanueva, N.D.M.; Silva M.A.A.P. 2007. Effect of nutrition and health claims on the acceptability of soyamilk beverages. International Journal of Food Science and Technology 42: 50-56.

Brasil. Ministério da Agricultura, Pecuária e Abastecimento. Instrução Normativa $n^{\circ} 22$, de 31 de julho de 2000. Regulamento Técnico de Identidade e Qualidade de Salame. 63pp.

Brasil. Ministério da Saúde. Agência Nacional de Vigilância Sanitária. Resolução RDC n ${ }^{\circ} 12$, de 02 de janeiro de 2001: Regulamento técnico sobre padrões microbiológicos para alimentos. Brasília, 2001. 148pp.

Carrillo, E.; Varela, P.; Fiszman, S. 2012. Packaging information as a modulator of consumers' perception of enriched and reduced-calorie biscuits in tasting and non-tasting tests. Food Quality and Preference 25: $105-115$.

Cichoski, A.J., Zis, L.C.; Franceschetto, C. 2009. Características físico-químicas e microbiológicas da superfície do salame tipo italiano contendo solução de lactato de potássio. Physicochemical and microbiological characteristics of the surface of Italian salami containing potassium lactate. Ciência e Tecnologia de Alimentos 3007: 546-552.

de Almeida, M.A.; Vilanueva, N.D.M.; Saldaña E. 2016. The use of Just-About-Right (JAR) scales to identify drivers of customer acceptance for low-sodium Italian salami. Meat Science 112: 112-112.

Desmond, E. 2006. Reducing salt: A challenge for the meat industry. Meat Science 74: 188-196.

dos Santos, B.A.; Bastianello, P.C.; Da Cruz, A.G. 2015. Check all that apply and free listing to describe the sensory characteristics of low sodium dry fermented sausages: Comparison with trained panel. Food Research International 76: 725-734.

Font-i-Furnols, M.; Guerrero, Luis. 2014. Preference, behavior and perception about meat and meat products: An overview. Meat Science 98: 361-371.

Guardia, M.D.; Guerrero, L.; Gelabert, J. 2006. Consumer attitude towards sodium reduction in meat products and acceptability of fermented sausages with reduced sodium content. Meat Science 73: 484-490.

Jaeger, S.R. 2006. Non-sensory factors in sensory science research. Food Quality and Preference 17: 132-144.

López, C.M.; Bru, E.; Vignolo, G.M. 2012. Main Factors Affecting the Consumer Acceptance of Argentinean Fermented Sausages. Journal of Sensory Studies 27: 304-313.

López, C.M.; Sentandreu, M.A.; Vignolo, G.M. 2015a. Low molecular weight peptides derived from sarcoplasmic proteins produced by an autochthonous starter culture in a beaker sausage model. EuPA Open Proteomics 7: 54-63.

López, C.M.; Sentandreu, M.A.; Vignolo, G.M. 2015b. Proteomic and peptidomic insights on myofibrillar protein hydrolysis in a sausage model during fermentation with autochthonous starter cultures. Food Research International 78: 41-49.

Marangoni, C.; Fernandes, N. 2011. Antioxidant activity of essential oil from Coriandrum Sativum L. in Italian salami. Food Science and Technology 31: 124-128.

Popper, R. 2014. Use of Just-About- Right Scales in Consumer Research. In: Varela P and Ares G (eds). Novel techniques in sensory characterization and consumer profiling. Boca Raton: CRC Press. pp. 137155. 
Quilaqueo, M.; Duizer, L.; Aguilera, J.M. 2015. The morphology of salt crystals affects the perception of saltiness. Food Research International 76: 675-681.

Rantsiou, K.; Cocolin, L. 2006. New developments in the study of the microbiota of naturally fermented sausages as determined by molecular methods: A review. International Journal of Food Microbiology 108: 255-267.

Rothman, L.; Parker, M.J. 2009. Just-About-Right (JAR) Scales: Design, Usage, Benefits and Risks. West Conshohocken: ASTM International.

WHO, 2012. Sodium intake for adults and children. World Health Organization - WHO. Guideline. Geneva. Disponível em: http://www.ilfattoalimentare.it/wp-
content/uploads/2013/03/OMS-Sodium-intake-foradults-children.pdf.

Xiong, R.; Meullenet, J.F. 2006. A PLS dummy variable approach to assess the impact of jar attributes on liking. Food Quality and Preference 17: 188-198.

Yotsuyanagi, S.E.; Castillo, C.J.C.; Haguiwara, M.M.H. 2015. Technological, sensory and microbiological impacts of sodium reduction in frankfurters. Meat Science 115: 50-59.

Zanardi, E.; Ghidini, S.; Battaglia, A. 2004. Lipolysis and lipid oxidation in fermented sausages depending on different processing conditions and different antioxidants. Meat Science 66: 415-423. 